\section{CNS Imaging is Essential in Acquired Bilateral Vocal Fold Dysfunction in Children}

\section{Dear Sir:}

I greatly enjoyed reading the paper by David and Lim on "Congenital Bilateral Vocal Fold Paralysis"1 ${ }^{\prime 1}$ and complement the authors on their excellent surgical outcome. They also very appropriately underscored the primacy of careful clinical assessment over costly investigations, particularly in an environment of scarce resources.

We have previously reported on the MRI findings in 23 children with bilateral vocal fold dysfunction (BVFD) as an isolated abnormality that was present at birth. We found MRI abnormalities in 35\%, but these were all non-specific. ${ }^{2}$ This study indicated that MRI was of research and clinical value but did not identify any major CNS structural abnormalities in this patient group.

However, the case reported by David and Lim involved the delayed onset of symptoms at two years of age that may have increased over the next three years. This acquired and possibly progressive disease process differs from that of congenital BVFD. The likelihood of ArnoldChiari malformation or another significant structural CNS abnormality being present would appear to be higher when symptoms of BVFD are acquired later in life compared to when they are present at birth.

Anecdotally, I have been involved with a case of acquired BVFD presenting at a similar age where the underlying cause was found to be a posterior fossa tumour. The 3-year history of symptoms in the child in the case report would very likely preclude this diagnosis but certainly another CNS cause needs to be considered to explain the development of delayed-onset brainstem dysfunction and this would require MRI.

Best wishes,

Robert G. Berkowitz, MD

Department of Otolaryngology

Royal Children's Hospital

50 Flemington Road Parkville Victoria 3052

Australia

\section{REFERENCES}

1. David RB, Lim WL. Congenital Bilateral Vocal Fold Paralysis in a Two-Year-Old Girl. Philipp J Otolaryngol Head Neck Surg 2014, 29(1):30-32.

2. Steiner Jl, Fink AM, Berkowitz RG. Magnetic Resonance Imaging Findings in Pediatric Bilateral Vocal Fold Dysfunction. Ann of Otol Rhinol Laryngol 2013, 122:417-420.

\section{Response from the Authors}

Dear Sir:

We would like to express appreciation for the comments given as well as for sharing your research findings in relation to the case.

We agree that a neurological problem must be properly ruled out most especially when there is a delayed onset of neurological symptoms with progression over time.

Indeed, the presence of vocal fold dysfunction in children should make one consider CNS pathologies most common of which is the Arnold- Chiari Malformation.

However, the following are our reasons for concurring with the pediatric neurology service in not requesting imaging:

1. Aside from vocal fold paralysis, no other neurological symptom or finding was noted such as presence of swallowing and feeding difficulties, dizziness or uncoordination usually present in brainstem pathologies manifesting with vocal fold paralysis such as Chiari Type I., ${ }^{1,2}$

2. Previous and subsequent neurological examinations showed a bilaterally intact gag reflex which somewhat made the possibility of a CNS lesion affecting the vagus unlikely. Furthermore, no findings indicative of cerebellar dysfunction (such as dysdiadokinesia) were noted.

Thank you very much.

Reylan B. David, MD

William L. Lim, MD

Department of Otorhinolaryngology

Head and Neck Surgery

Saint Luke's Medical Center

279 E. Rodriguez Ave., Quezon City 1102

Philippines

\section{REFERENCES}

1. Greenlee JD, Donovan KA, Hasan DM, Menezes AH. Chiari I malformation in the very young child: the spectrum of presentations and experience in 31 children under age 6 years. Pediatrics. 2002 Dec;110(6):1212-9.

2. Aitken LA, Lindan CE, Sidney S, Gupta N, Barkovich AJ, Sorel M, Wu YW.Chiari type I malformation in a pediatric population. Pediatr Neurol. 2009 Jun;40(6):449-54. doi: 10.1016/j. pediatrneurol.2009.01.003. 